\title{
REVIEW OF INDONESIAN NATIONAL WORK COMPETENCY STANDARDS FROM THE PROFESSIONAL STANDARDIZATION NATIONAL AGENCY IN CREATIVE MEDIA STANDARD POLYTECHNICS JAKARTA
}

\author{
Zalzulifa ${ }^{1}$, Nasaruddin ${ }^{2}$, Purnomo ${ }^{3}$ \\ $1 \& 3$ Politeknik Negeri Media Kreatif \\ 2Sekolah Tinggi Keguruan Dan Ilmu Pendidikan (STKIP) Pancakarya Tangrerang \\ E-mail: zalzulifar@yahoo.com¹, nasrudin@gmail.com², purnomo_mm@yahoo.com
}

\begin{abstract}
The research objective is to describe and interpret the extent to which the level of requirements for the Indonesian National Work Competency Standards (SKKNI) from the National Professional Standardization Agency (BNSP) applied to the State Polytechnic of Creative Media (PoliMedia) ". The research method used is quantitative research methods with the approach used is descriptive, namely a strategy that aims to describe a phenomenon and its characteristics by collecting data in the form of numbers. The population is only 19 people, so the sample used is a total sample of 19 people, so this research is called population research. The collection technique used a closed questionnaire, in which 19 practitioners of the book publishing industry answered questions (questionnaires) with four answer choices, namely; unnecessary scores (1), need not scores (2), need scores (3) and, urgently need scores (4). Questions regarding competency units as guidelines for the preparation of SKKNI from the National Professional Standardization Agency (BNSP) must be applied to the State Polytechnic of Creative Media (PoliMedia). Analysis of the research data was descriptive analysis with the help of SPSS 22.00. The results of the research as a whole, the level of the need for the competency unit as a guide for the preparation of the National Agency for Professional Standardization (BNSP) applied to the Creative Media State Polytechnic (PoliMedia) was $86.8 \%$ of the expected $100 \%$.
\end{abstract}

Keyword: Indonesian National work competency standards, National Professional Standards Agency,

\section{KAJI ULANG STANDAR KOMPETENSI KERJA NASIONAL INDONESIA (SKKNI) DARI BADAN NASIONAL STANDARISASI PROFESI (BNSP) PADA POLITEKNIK NEGERI MEDIA KREATIF (POLIMEDIA) JAKARTA}

\begin{abstract}
ABSTRAK Tujuan penelitian adalah mendeskripsikan dan menafsirkan sejauhmana tingkat keperluan standar kompetensi kerja Nasional Indonesia (SKKNI) dari Badan Nasional Standarisasi Profesi (BNSP) yang diterapkan pada Politeknik Negeri Media Kreatif (PoliMedia)". Metode penelitian yang digunakan adalah metode penelitian kuantitatif dengan pendekatan yang digunakan adalah deskriptif yaitu suatu pendektan yang bertujuan mendeskripsikan suatu fenomena dan karakteristiknya dengan mengumpulkan data berupa angka. Populasi hanya 19 orang, maka sampel yang digunakan adalah sampel total yaitu sebanyak 19 orang, maka penelitian ini disebut penelitian populasi. Teknik pengumpulan dengan menggunakan questioner tertutup, yang mana 19 orang praktisi industri penerbitan buku mejawab pertanyaan (angket) dengan empat pilihan jawaban yaitu; sangat tidak perlu skor (1), tidak perlu skor (2), perlu skor (3) dan, sangat perlu skor (4). Pertanyaanpertanyaan mengenai unit kompetensi sebagai panduan penyusunan SKKNI dari Badan Nasional Standarisasi Profesi (BNSP) harus diterapkan pada Politeknik Negeri Media Kreatif (PoliMedia). Analisis data hasil penelitian adalah analisis secara deskriptif dengan bantuan SPSS 22.00. Hasil penelitian secara keseluruhan tingkat keperluan unit kompetensi sebagai panduan penyusunan SKKNI dari Badan Nasional Standarisasi Profesi (BNSP) yang dterapkan pada Politeknik Negeri Media Kreatif (PoliMedia) sebesar 86.8\% dari yang diharapkan $100 \%$.

Kata kunci: standar kompetensi kerja Nasional Indonesia, Badan Nasional Standar Profesi,
\end{abstract}




\section{PENDAHULUAN}

Pentingnya penelitian ini berasal dari fakta bahwa, sebagian besar lulusan politeknik program studi penerbitan menjadi tenaga ahli siap pakai dan menadi penentu keberhasilan perusahaan khususnya perusahaan penerbit. Salah satu cara untuk meningkatkan efektivitas industri penerbit adalah dengan meningkatkan kompetensi lulusan program studi. Bagi pengelola program studi penerbit di Politeknik Negeri Media Kreatif (PoliMedia) ada semacam kekhawatiran tentang komptensi lulusan. Oleh karena itu, penting untuk melakukan pengkajian ulang mengenai keperluan-keperluan yang mendukung peningkatan komptensi lulusan sejalan dengan hadirnya industry kreatif yang selalu meminta komptensi sumber daya manusia (lulusan) sebagai faktor kunci keberhasilan usaha, kususunya usaha bidang penerbit yang merupakan bagian dari industry kreatif.

Pengembangan industri kreatif di Indonesia semakin intensif diupayakan sejak dideklarasikannya tahun 2009 sebagai "tahun industri kreatif nasional". Sejalan dengan itu, Politeknik Negeri Media Kreatif (PoliMedia) didirikan sebagai institusi pendidikan tinggi yang ditugaskan untuk mempersiapkan SDM yang potensial menunjang pertumbuhan industri kreatif nasional. Untuk menghasilan lulusan yang siap kerja, Pimpinan Politeknik Negeri Media Kreatif (PoliMedia) menyadari pentingnya Standar Kompetensi Kerja Nasional Indonesia (SKKNI) sebagai acuan arah pendidikan dan mutu lulusan yang akan digunakan Industri.

Dalam studi penelusuran SKKNI Penerbitan tahun 2008 dengan rujukan utama standar kompetensi Penerbitan Inggris, terdapat 9 Skema, 39 Unit Kompetensi, dan 134 Elemen Kompetensi. Untuk memastikan proses lanjut adaptasi diperlukan tahapan uji relevansi guna memastikan kebenaran baik aspek tugas, aspek kompetensi maupun elemen kompetensi sesuai panduan penyusunan SKKNI dari Badan Nasional Standarisasi Profesi (BNSP). Akan tetapi SKKNI Penerbitan versi Indonesia yang disahkan berdasarkan SK Kemenakertrans Nomor 124 Tahun 2018 Tentang "penetapan Standar Kompetensi Kerja Nasional Indonesia kategori informasi dan komunikasi golongan pokok aktivitas penerbitan bidang penerbitan buku". Fungsi dasar diadopsi dari SKKNI Keputusan Menteri Tenaga Kerja dan Transmigrasi Republik Indonesia Nomor 83 Tahun 2012 tentang Penetapan Unit kompetensi ini berhubungan dengan pengetahuan, keterampilan, dan sikap kerja yang dibutuhkan seperti: 1) mengidentifikasi dan mengevaluasi potensi pasar sehubungan dengan jenis naskah yang akan diterbitkan; 2) mengidentifikasi dan mengevaluasi prioritas tujuan dan sumber daya perusahaan penerbitan; 3) mengkaji ulang rencana penerbitan yang telah dibuat apakah layak atau tidak; 4) memilih penulis, kontributor, pengembang dan penyelia naskah yang cocok dan kompeten; 5) merundingkan dan menyepakati kerja sama penerbitan dengan para penulis, contributor, pengembang dan penyelia naskah; 6) menetapkan dan mempersiapkan sumberdaya untuk keperluan editorial; 7) menyunting naskah; 8) membuat estimasi dan melakukan pengendalian biaya produksi; 9) memastikan dan menghitung biaya produksi, membuat estimasi dan melakukan pengendalian biaya publikasi elektronik; 10) menyiapkan dan membuat spesifikasi publikasi; 11) memberikan dukungan penjualan langsung dan kepuasan pelanggan

Setelah tiga tahun penerapan diperlukan langkah kaji ulang agar proses harmonisaai dan ketertelusuran kompetensi SDM Penerbitan dapat disejajarkan antar negara dan bangsa. Standar kompetensi SDM Penerbitan yang ada di Inggris dan Amerika dan Indonesia 
sangat diperlukan untuk dipelajari lebih mendalam mengenai Standar Kompetensi Kerja Nasional Indonesia (SKKNI) dari Badan Nasional Standarisasi Profesi (BNSP) sebagai acuan bagi lulusan pendidikan vokasi bidang penerbit khususnya Politeknik Negeri Media Kreatif (PoliMedia).

Untuk memperoleh informasi yang diperlukan standar Standar Kompetensi Kerja Nasional Indonesia (SKKNI) dari Badan Nasional Standarisasi Profesi (BNSP) harus diterapkan pada Politeknik Negeri Media Kreatif (PoliMedia) dalam penelitian ini diperoleh dari para praktisi bidang penerbit, mereka diminta keterangan berdasarkan presepsi mereka masingmasing selama menjadi pengusaha bidang penerbit yang mana bagian dari industry kreatif di Indonesia.

Agar kajian tidak melenceng jauh dari tujuan penelitian mengenai kaji ulang relevansi standar kompetensi kerja nasional Indonesia (SKKNI) dari badan nasional standarisasi profesi (BNSP) yang diterapkan pada Politeknik Negeri Media Kreatif (PoliMedia) maka penelitian hanya berfokus pada unit kompetensi sebagai panduan penyusunan SKKNI dari Badan Nasional Standarisasi Profesi (BNSP) yang meliputi; 1) mengidentifikasi dan mengevaluasi potensi pasar sehubungan dengan jenis naskah yang akan diterbitkan; 2) mengidentifikasi dan mengevaluasi prioritas tujuan dan sumber daya perusahaan penerbitan; 3) mengkaji ulang rencana penerbitan yang telah dibuat apakah layak atau tidak; 4) memilih penulis, kontributor, pengembang dan penyelia naskah yang cocok dan kompeten; 5) merundingkan dan menyepakati kerja sama penerbitan dengan para penulis, contributor, pengembang dan penyelia naskah; 6) menetapkan dan mempersiapkan sumberdaya untuk keperluan editorial; 7) menyunting naskah; 8) membuat estimasi dan melakukan pengendalian biaya produksi; 9) memastikan dan menghitung biaya produksi, membuat estimasi dan melakukan pengendalian biaya publikasi elektronik; 10) menyiapkan dan membuat spesifikasi publikasi; 11) memberikan dukungan penjualan langsung dan kepuasan pelanggan.

Rumusan masalah berupa pemetaan studi agar lebih terfokus dan tearah dalam proses pencarian data dan membuat kesimpulan. Adapaun rumusan masalah secara umum adalah "Sejauhmana tingkat keperluan unit kompetensi sebagai panduan penyusunan SKKNI dari Badan Nasional Standarisasi Profesi (BNSP) yang diterapkan pada Politeknik Negeri Media Kreatif (PoliMedia) yang meliputi; 1) mengidentifikasi dan mengevaluasi potensi pasar sehubungan dengan jenis naskah yang akan diterbitkan; 2) mengidentifikasi dan mengevaluasi prioritas tujuan dan sumber daya perusahaan penerbitan; 3) mengkaji ulang rencana penerbitan yang telah dibuat apakah layak atau tidak; 4) memilih penulis, kontributor, pengembang dan penyelia naskah yang cocok dan kompeten; 5) merundingkan dan menyepakati kerja sama penerbitan dengan para penulis, contributor, pengembang dan penyelia naskah; 6) menetapkan dan mempersiapkan sumberdaya untuk keperluan editorial; 7) menyunting naskah; 8) membuat estimasi dan melakukan pengendalian biaya produksi; 9) memastikan dan menghitung biaya produksi, membuat estimasi dan melakukan pengendalian biaya publikasi elektronik; 10) menyiapkan dan membuat spesifikasi publikasi; 11) memberikan dukungan penjualan langsung dan kepuasan pelanggan.

\section{METODE PENELITIAN}

Metode penelitian yang digunakan adalah metode penelitian kuantitatif yaitu penelitian yang menganut paradigma positivism yang mana segala realitas adalah objektif tunggal, bebas nilai dan, terpisah 
dari peneliti (Jhon W. Creswell, 1994 dalam Emzir, 2012)

\section{a. Pendekatan Penelitain}

Adapun pendekatan yang digunakan adalah deskriptif yaitu suatu pendektan yang bertujuan mendeskripsikan suatu fenomena dan karakteristiknya dengan mengumpulkan data berupa angka yang digunakan untuk mengukur opini, sikap, perilaku, dan variabel lain yang ditentukan untuk mendukung atau menyangkal fenomena tertentu. (Gall, \& Borg, 2007)

\section{b. Populasi Dan Sampel}

Populasi dapat diartikan sebagai sekelompok individu, institusi, objek dan sebagainya yang memiliki kesamaan karakteristik yang menjadi minat seorang peneliti. Ciri umum kelompok membedakan mereka dari individu lain, lembaga, objek dan sebagainya. Adapun jumlah populasi dalam penelitian ini sebanyak 19 orang ahli yang memiliki pengetahuan lebih tentang permasalahan yang diteliti. Sedangkan sampel dapat didefinisikan sebagai sebagian kecil dari populasi yang dipilih untuk studi tertentu. Sampel harus secara jelas mewakili karakteristik kelompok yang dituju. Berhubung dengan jumlah populasi hanya 19 orang, maka sampel yang digunakan adalah sampel total yaitu sebanyak 19 orang, maka penelitian ini disebut penelitian populasi (Arikonto Suharsimi, 2004)

\section{c. Sumber Data}

Secara garis besar terdapat dua sumber data yang digunakan yaitu: sumbr data primer dan sumber data sekunder. Sumber data primer yaitu jawaban dari hasil pertanyaan terbuka dari para praktisi bidang penerbitan buku yang sudah berpengalaman bertahun-tahun sebanyak 19 orang. Mereka dipilih secara sengaja karean telah dianggap memiliki pengetahuan lebih di bidangnya. Kemudian sumber data sekunder berupa hasil kajiankajian yang relevan seperti artikel ilmiah, buku dan internet.

\section{d. Validitas dan Realibilitas Instrumen}

Hal yang terpenting dalam penelitian kuantitatif adalah kualitas instrument sebagai alat pengumpulan data. Instrument yang berkualitas yaitu yang memiliki tingkat validitas dan realibilitas yang baik. Validitas artinya ketepatan instrument sebagai alat ukur sedangakan realibilitas artinya keandalan atau ketetapan apa yang diukur (Sugiyono, 2009: Arikunto, 2004). Tingkat validitas hasil pengukuran dapat dilihat dari nilai $p$-value $\leq 0.05$. Untuk melihat tingkat realibilitas dapat dilihat dari nilai Croanbach $\geq 0.60$ (Sugiyono, 2009)

\section{e. Teknik Pengumpulan Data}

Adapun teknik pengumpulan dengan menggunakan questioner tertutup, yang mana 19 orang praktisi industri penerbitan buku mejawab pertanyaan (angket) dengan empat pilihan jawaban yaitu; sangat tidak perlu skor (1), tidak perlu skor (2), perlu skor (3) dan, sangat perlu skor (4). Pertanyaan-pertanyaan mengenai unit kompetensi sebagai panduan penyusunan SKKNI dari Badan Nasional Standarisasi Profesi (BNSP) harus diterapkan pada Politeknik Negeri Media Kreatif (PoliMedia)

\section{f. Analisis Data}

Sesuai dengan jenis penelitian yang digunakan maka, analisis data hasil penelitian adalah analisis secara deskriptif dengan bantuan SPSS 22.00 yang berhubungan aspek-aspek penting seperti ukuran pemusatan yang sering digunakan terdiri dari nilai rata-rata, median, modus dll. Agar mudah dibaca maka data hasil penelitian disajikan dalam bentuk tabel dan grafik.

\section{HASIL DAN PEMBAHASAN}

Hasil penelitian menegnai relevansi unit kompetensi sebagai panduan penyusunan SKKNI dari Badan Nasional Standarisasi Profesi (BNSP) yang diterapkan pada Politeknik Negeri Media Kreatif (PoliMedia) yang meliputi; 1) mengidentifikasi dan mengevaluasi potensi 
pasar sehubungan dengan jenis naskah yang akan diterbitkan; 2) mengkaji ulang rencana penerbitan yang telah dibuat apakah layak atau tidak; 3) memilih penulis, kontributor, pengembang dan penyelia naskah yang cocok dan kompeten; 4) merundingkan dan menyepakati kerja sama penerbitan dengan para penulis, contributor, pengembang dan penyelia naskah; 5) menetapkan dan mempersiapkan sumberdaya untuk keperluan editorial; 6) menyunting naskah; 7) membuat estimasi dan melakukan pengendalian biaya produksi; 8) memastikan dan menghitung biaya produksi, membuat estimasi dan melakukan pengendalian biaya publikasi elektronik; 9) menyiapkan dan membuat spesifikasi publikasi; 10) memberikan dukungan penjualan langsung dan kepuasan pelanggan.

\section{Uji Validitas dan Realibilitas}

Tabel 1

Hasil Validitas Dan Realibilitas SKKNI dari (BNSP) pada Politeknik Negeri Media Kreatif (PoliMedia)

\begin{tabular}{|l|c|c|c|}
\hline Kode & $\begin{array}{c}\text { Scale Mean if } \\
\text { Item Deleted }\end{array}$ & $\begin{array}{c}\text { Scale Variance } \\
\text { if Item Deleted }\end{array}$ & $\begin{array}{c}\text { Corrected } \\
\text { Item-Total } \\
\text { Correlation }\end{array}$ \\
\hline Q20 & 65.7368 & 46.427 & 0.411 \\
Q25 & 66.0000 & 43.667 & 0.410 \\
Q28 & 66.0526 & 44.275 & 0.407 \\
Q29 & 65.8947 & 44.099 & 0.429 \\
Q69 & 66.0000 & 42.556 & 0.764 \\
Q112 & 66.0000 & 44.111 & 0.522 \\
Q114 & 65.9474 & 42.053 & 0.844 \\
Q115 & 66.0000 & 42.111 & 0.834 \\
Q124 & 66.1579 & 41.918 & 0.752 \\
Q161 & 66.2105 & 43.287 & 0.585 \\
\hline
\end{tabular}

Berdasarkan output SPSS 22.00 pada tabel 1 di atas, hasil uji validitas dan realibitas unit kompetensi sebagai panduan penyusunan SKKNI dari Badan Nasional Standarisasi Profesi (BNSP) yang diterapkan pada Politeknik Negeri Media Kreatif (PoliMedia) yang terdiri dari item pernyataan yang berkode Q20, Q25, Q28, Q28, Q69, Q112, Q114, Q115, Q124 dan Q161 diperoleh nilai $r_{\text {hitung }} \geq r_{\text {tabel }} n-2=19-2=17$ a $0.05=0.455$, dengan demikian item-item tersebut dianggap valid.

\section{Tanggapan Ahli (responden)}

Tanggapan responden mengenai relevansi unit kompetensi sebagai panduan penyusunan SKKNI dari Badan Nasional Standarisasi Profesi (BNSP) yang diterapkan pada Politeknik Negeri Media Kreatif (PoliMedia) sebagai berikut:

a. Mengidentifikasi dan mengevaluasi potensi pasar sehubungan dengan jenis naskah yang akan diterbitkan.

Tabel 2 Kode Q20

\begin{tabular}{|c|c|c|c|c|}
\hline \multicolumn{2}{|c|}{ Jawaban } & $\begin{array}{c}\text { Frequenc } \\
\mathrm{y}\end{array}$ & $\begin{array}{c}\text { Valid } \\
\text { Percent }\end{array}$ & $\begin{array}{c}\text { Cumulative } \\
\text { Percent }\end{array}$ \\
\hline \multirow[t]{3}{*}{ Valid } & Perlu & 5 & 26.3 & 26.3 \\
\hline & $\begin{array}{l}\text { Sangat } \\
\text { Perlu }\end{array}$ & 14 & 73.7 & 100.0 \\
\hline & Total & 19 & 100.0 & \\
\hline
\end{tabular}

Hasil output SPSS 22.00 kode Q2 dari 19 orang ahli bahwa $73.7 \%$ menjawab sangat perlu dilakukan dan $26.3 \%$ yang menjawab perlu dilakukan, dengan demikian dapat disimpulkan, tingkat keperluan dalam mengidentifikasi dan mengevaluasi potensi pasar sehubungan होधngakfts Janis naskah yang akan diterbitkan Alphpirfotgmam studi penerbit Politeknik Negeri

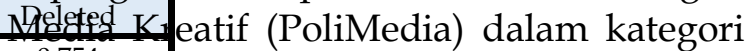
ting.g. dan wajib memiliki komptensi di bideamn te ssebut, kerena memiliki relevansi deritoan d unia penerbit.

$b_{\cdot 0.737}$ Mengkaji ulang rencana penerbitan 0.719 yan $\beta$ telah dibuat apakah layak atau 0.719 tidak

\begin{tabular}{|c|c|c|c|}
\hline awaban & $\begin{array}{c}\text { Frequenc } \\
\mathrm{y}\end{array}$ & $\begin{array}{c}\text { Valid } \\
\text { Percent }\end{array}$ & $\begin{array}{c}\text { Cumulative } \\
\text { Percent }\end{array}$ \\
\hline $\begin{array}{ll}\text { Valid } & \text { Tidak } \\
& \text { Perlu }\end{array}$ & 2 & 10.5 & 10.5 \\
\hline Perlu & 6 & 31.6 & 42.1 \\
\hline $\begin{array}{l}\text { Sangat } \\
\text { Perlu }\end{array}$ & 11 & 57.9 & 100.0 \\
\hline Total & 19 & 100.0 & \\
\hline
\end{tabular}

Hasil output SPSS 22.00 kode Q25 dari 19 orang ahli bahwa $10.5 \%$ menjawab tidak perlu dilakukan $10.5 \%$, yang 
menjawab perlu dilakukan $31.6 \%$ dan yang menjawab sangat perlu dilakukan $57.9 \%$. Karena yang menjawab sangat perlu dan perlu lebih besar dari yang menjawab tidak perlu, dengan demikian dapat disimpulkan, tingkat keperluan dalam mengkaji ulang rencana penerbitan yang telah dibuat apakah layak atau tidak di Politeknik Negeri Media Kreatif (PoliMedia) dalam kategori sangat cukup dan wajib memiliki komptensi di bidang tersebut, kerena memiliki relevansi dengan dunia penerbit.

c. Memilih penulis, kontributor, pengembang dan penyelia naskah yang cocok dan kompeten

\begin{tabular}{|c|c|c|c|}
\hline Jawaban & Frequency & $\begin{array}{c}\text { Valid } \\
\text { Percent }\end{array}$ & $\begin{array}{c}\text { Cumulative } \\
\text { Percent }\end{array}$ \\
\hline Tidak 1 & 5.3 & 5.3 & 10.5 \\
\hline Perlu 9 & 47.4 & 52.6 & 42.1 \\
\hline $\begin{array}{l}\text { Perlu } 9 \\
\text { Sng }\end{array}$ & 47.4 & 100.0 & 100.0 \\
\hline Perlu 19 & 100.0 & & \\
\hline Total & & & \\
\hline
\end{tabular}

d. Merundingkan dan menyepakati kerja sama penerbitan dengan para penulis, contributor, pengembang dan penyelia naskah

Tabel 5 Kode Q29

\begin{tabular}{|ll|c|c|c|}
\hline Jawaban & & $\begin{array}{c}\text { Freque } \\
\text { ncy }\end{array}$ & $\begin{array}{c}\text { Valid } \\
\text { Percent }\end{array}$ & $\begin{array}{c}\text { Cumulative } \\
\text { Percent }\end{array}$ \\
\hline Valid & Tidak & 1 & 5.3 & 10.5 \\
& Perlu & 1 & 31.6 & 42.1 \\
& Perlu & 6 & 31.6 & 100.0 \\
& Sangat & 12 & 63.2 & \\
& Perlu & & \\
& Total & 19 & 100.0 & \\
\hline
\end{tabular}

Hasil output SPSS 22.00 kode Q29 dari 19 orang ahli bahwa menjawab tidak perlu dilakukan $5.3 \%$ yang menjawab perlu dilakukan $31.6 \%$, dan yang menjawab sangat perlu dilakukan $63.2 \%$. Karena yang menjawab sangat perlu dan perlu lebih besar dari yang menjawab tidak perlu, dengan demikian dapat disimpulkan, tingkat keperluan dalam merundingkan dan menyepakati kerja sama penerbitan dengan para penulis, contributor, pengembang dan penyelia naskah di program studi penerbit Politeknik Negeri Media Kreatif (PoliMedia) dalam kategori sangat tinggi dan lulusan wajib memiliki komptensi di bidang tersebut, kerena memiliki relevansi dengan dunia penerbit.

\section{e. Menetapkan dan mempersiapkan sumberdaya untuk keperluan editorial}

Tabel 6 Kode Q69

\begin{tabular}{|c|c|c|c|c|}
\hline Jawaban & & Frequency & $\begin{array}{l}\text { Valid } \\
\text { Percent }\end{array}$ & $\begin{array}{c}\text { Cumulative } \\
\text { Percent }\end{array}$ \\
\hline \multirow[t]{3}{*}{ Valid } & Perlu & 10 & 52.6 & \multirow{3}{*}{$\begin{array}{l}\text { Valid } \\
100.0\end{array}$} \\
\hline & $\begin{array}{l}\text { Sangat } \\
\text { Perlu }\end{array}$ & 9 & 47.4 & \\
\hline & Total & 19 & 100.0 & \\
\hline
\end{tabular}

Hasil output SPSS 22.00 kode Q69 dari 19 orang ahli bahwa menjawab tidak perlu dilakukan $0 \%$, yang menjawab perlu dilakukan $52.6 \%$, dan yang menjawab sangat perlu dilakukan $47.4 \%$. Karena hanya menjawab sangat perlu saja, dengan demikian dapat disimpulkan, tingkat keperluan dalam mempersiapkan sumberdaya untuk keperluan editorial di program studi penerbit Politeknik Negeri Media Kreatif (PoliMedia) dalam kategori cukup dan lulusan wajib memiliki komptensi di bidang tersebut, kerena memiliki relevansi dengan dunia penerbit.

f. Menyunting Naskah Tabel 7 Kode Q112

\begin{tabular}{|ll|c|c|c|}
\hline Jawaban & Frequency & $\begin{array}{c}\text { Valid } \\
\text { Percent }\end{array}$ & $\begin{array}{c}\text { Cumulative } \\
\text { Percent }\end{array}$ \\
\hline Perlu 10 & 52.6 & 52.6 & Valid \\
Sangat 9 & 47.4 & 100.0 & 100.0 \\
Perlu 19 & 100.0 & & \\
Total 19 & & \\
\hline
\end{tabular}

Hasil output SPSS 22.00 kode Q112 dari 19 orang ahli bahwa menjawab tidak perlu dilakukan $0 \%$, yang menjawab perlu dilakukan $52.6 \%$, dan yang menjawab sangat perlu dilakukan $47.4 \%$. Karena hanya menjawab sangat perlu saja, dengan demikian dapat disimpulkan, tingkat 
keperluan dalam menyunting naskah di program studi penerbit Politeknik Negeri Media Kreatif (PoliMedia) dalam kategori cukup dan lulusan wajib memiliki komptensi di bidang tersebut, kerena memiliki relevansi dengan dunia penerbit.

g. Membuat estimasi dan melakukan pengendalian biaya produksi

Tabel 8 Kode Q114

\begin{tabular}{|ll|c|c|c|}
\hline \multicolumn{2}{|l|}{ Jawaban } & Frequency & $\begin{array}{c}\text { Valid } \\
\text { Percent }\end{array}$ & $\begin{array}{c}\text { Cumulative } \\
\text { Percent }\end{array}$ \\
\hline Valid & Tidak & 1 & 5.3 & 5.3 \\
& Perlu & 11 & 57.9 & 63.2 \\
& Perlu & 7 & 36.8 & 100.0 \\
& Sangat & 7 & 100.0 & \\
\hline & Perlu & 19 & \\
\hline
\end{tabular}

Hasil output SPSS 22.00 kode Q124 dari 19 orang ahli bahwa menjawab tidak perlu dilakukan $5.3 \%$, yang menjawab perlu

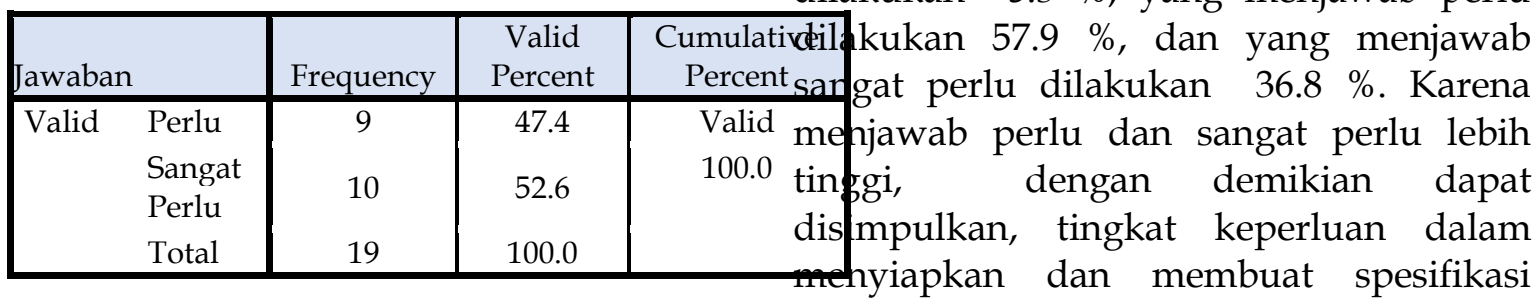

h. Memastikan dan menghitung biaya produksi, membuat estimasi dan melakukan pengendalian biaya publikasi elektronik

Tabel 9 Kode Q115

\begin{tabular}{|c|c|c|c|c|}
\hline Jawaban & & Frequency & $\begin{array}{c}\text { Valid } \\
\text { Percent }\end{array}$ & $\begin{array}{r}\text { Cumulati } \\
\text { Percent }\end{array}$ \\
\hline \multirow[t]{3}{*}{ Valid } & Perlu & 10 & 52.6 & 52.6 \\
\hline & $\begin{array}{l}\text { Sangat } \\
\text { Perlu }\end{array}$ & 9 & 47.4 & 100.0 \\
\hline & Total & 19 & 100.0 & \\
\hline
\end{tabular}

Hasil output SPSS 22.00 kode Q115 dari 19 orang ahli bahwa menjawab tidak perlu dilakukan $0 \%$, yang menjawab perlu dilakukan $52.6 \%$, dan yang menjawab sangat perlu dilakukan $47.4 \%$. Karena hanya menjawab perlu dan sangat perlu saja, dengan demikian dapat disimpulkan, tingkat keperluan dalam memastikan dan menghitung biaya produksi, membuat estimasi dan melakukan pengendalian biaya publikasi elektronik di Politeknik Negeri Media Kreatif (PoliMedia) dalam kategori cukup dan lulusan wajib memiliki komptensi di bidang tersebut, kerena memiliki relevansi dengan dunia penerbit.

\section{i. Menyiapkan dan membuat spesifikasi publikasi}

Tabel 10 Kode Q124 publikasi di Politeknik Negeri Media Kreatif (PoliMedia) dalam kategori cukup dan lulusan wajib memiliki komptensi di bidang tersebut, kerena memiliki relevansi dengan dunia penerbit

jं Memberikan dukungan penjualan langsung dan kepuasan pelanggan

Tabel 11 Kode Q161

\begin{tabular}{|ll|c|c|c|}
\hline \multicolumn{2}{|l|}{ Jawaban } & $\begin{array}{c}\text { Freque } \\
\text { ncy }\end{array}$ & $\begin{array}{c}\text { Valid } \\
\text { Percent }\end{array}$ & $\begin{array}{c}\text { Cumulative } \\
\text { Percent }\end{array}$ \\
\hline Valid & Tidak & 1 & 5.3 & 5.3 \\
& $\begin{array}{l}\text { Perlu } \\
\text { Perlu }\end{array}$ & 12 & 63.2 & 68.4 \\
& $\begin{array}{l}\text { Sangat } \\
\text { Perlu } \\
\text { Total }\end{array}$ & 6 & 31.6 & 100.0 \\
\hline
\end{tabular}

Hasil output SPSS 22.00 kode Q161 dari 19 orang ahli bahwa menjawab tidak perlu dilakukan $5.3 \%$, yang menjawab perlu dilakukan $63.2 \%$, dan yang menjawab sangat perlu dilakukan $31.6 \%$. Karena menjawab perlu dan sangat perlu lebih tinggi, dengan demikian dapat disimpulkan, tingkat keperluan dalam memberikan dukungan penjualan langsung dan kepuasan pelanggan di program studi penerbit Politeknik Negeri Media Kreatif (PoliMedia) dalam kategori tinggi dan lulusan wajib memiliki komptensi di bidang tersebut, kerena memiliki relevansi dengan 
dunia penerbit. Skor total jawaban ahli (responden) mengenai unit kompetensi sebagai panduan penyusunan SKKNI dari Badan Nasional Standarisasi Profesi (BNSP) pada Politeknik Negeri Media Kreatif (PoliMedia) disajikan pada tabel berikut:

\begin{tabular}{|l|r|}
\hline $\mathrm{N}$ & Valid \\
Mean & 0 \\
Std. Error of Mean & 34.7368 \\
Median & .79414 \\
Mode & 34.0000 \\
Std. Deviation & 32.00 \\
Variance & 3.46157 \\
Range & 11.982 \\
Minimum & 11.00 \\
Maximum & 29.00 \\
Sum & 40.00 \\
\hline
\end{tabular}

Berdasarkan output SPSS 22.00 total jawaban dari 19 ahli pada tabel 12 di atas bahwa jumlah banyak data $\mathrm{n}=19$, missing $=0$ (tidak ada data yang tertinggal), ratarata $=34.73$, standar error rata-rata $=0.79$, median $=34.00$, modus $=32.00$, simpangan baku $=3.46$, varian $=11.98$, jangkauan $=$ 11.00, skor minimum $=29.00$, skor maximum $=40$ dan, jumlah skor observasi $=660.00$. Sedang jumlah skor kriterium $=4$ x $10 \times 19=760$ (jika 19 orang memilih jawaban sangat penting dengan skor 4 untuk 10 item pertanyaan). Jumlah skor observasi dibagi dengan skor kriterium = $660.00: 760 \times 100=86.8 \%$. Secara kontinum sebagai berikut:

\begin{tabular}{|l|r|r|r|}
\hline $\begin{array}{l}\text { Pilihan } \\
\text { jawaban }\end{array}$ & $\begin{array}{r}\text { Sangat } \\
\text { Tidak } \\
\text { Perlu }\end{array}$ & $\begin{array}{r}\text { Tidak } \\
\text { Perlu }\end{array}$ & Perlu \\
\hline Skor & 1 & 2 & 3 \\
\hline Persen & $25 \%$ & $50 \%$ & $75 \%$ \\
\hline
\end{tabular}

Berdasarkan hasil perhitungan di atas diperoleh jawaban responden secara keseluruhan sebesar $86.8 \%$ berada di sekitar (jawaban sangat perlu). Artinya secara keseluruhan tingkat keperluan unit kompetensi sebagai panduan penyusunan SKKNI dari Badan Nasional Standarisasi Profesi (BNSP) yang dterapkan pada Politeknik Negeri Media Kreatif
(PoliMedia) sebesar $86.8 \%$ dari yang diharapkan $100 \%$.

\section{k. Diskusi Teoretik}

Hasil penelitian mengenai Unit kompetensi sebagai panduan penyusunan SKKNI dari Badan Nasional Standarisasi Profesi (BNSP) yang dterapkan pada Politeknik Negeri Media Kreatif (PoliMedia) ditemukan secara keseluruhan sebesar $86.8 \%$, Artinya secara keseluruhan penerapan unit-unit kompetensi masih dalam kategori sangat baik seperti yang dikatakan Tucker dan Cofsky (1994), bahwa kompotensi yang berkaitan dengan bidang tugas yang didukung oleh pengalaman, keterampilan, konsep diri dan, image. penerapan komptensi dari hasil temuan ini mendukung pernyataan Katz dan Kahn (1966) yang membagi kompetensi terdiri dari bidang keahlian; a) teknis / fungsional seperti pengetahuan, sikap dan keterampilan; b) bidang manajemen seperti pengetahuan dan keterampilan; c) konseptual kapasitas menggunakan intuisi dalam perencanaan bisnis masa depan.

Hasil temuan secara khusus merupakan bagian dari Unit kompetensi sebagai panduan penyusunan SKKNI dari Badan Nasional Standarisasi Profesi (BNSP) yang dterapkan pada Politeknik Negeri Media Kreatif (PoliMedia) ditemukan bahwa; komptensi dalam mengidentifikasi dan mengevaluasi potensi pasar sehubungan demgan jenis naskah yang akan diterbitkan seleckbr $73.7 \%$ dalam kategori tinggi artin $\$$ a komptensi yang berkaitan dengan habo\%ini diperlukan bagi untuk untuk mendukung pelaksanaan pekerjaan di bidang penerbit buku, seperti yang nyatakan Kinkel dkk. (2017) yaitu kompetensi untuk mendefinisikan kemampuan disposisional individu dan kesiapan untuk bertindak dengan sukses dan dengan cara yang terorganisir sendiri ketika menghadapi situasi atau tugas baru. Komptensi dalam mengkaji ulang rencana penerbitan yang telah dibuat apakah layak 
atau tidak. Pada bagian ini hasil penelitian ditemukan bahwa penerapan sebesar $57.9 \%$ dalam kategori cukup. komptensi yang dibutuhkan Pada tahap memulai bisnis studi kelayakan berbagai aspek pendukung yang membantu kelancaran bisnis harus dipelajari layak atau tidaknya. Bisnis yang sukses bisnis yang mampu mengurangi resiko kerugian sebagaimana yang dikatakan Hogg (1993) bahwa kompetensi adalah karakteristik seorang yang memandu demonstrasi keterampilan dan kemampuan yang berkontribusi pada hasil yang sukses.

Hasil temuan mengenai komptensi dalam memilih penulis, kontributor, pengembang dan penyelia naskah yang cocok dan kompeten, komptensi dalam merundingkan dan menyepakati kerja sama penerbitan dengan para penulis, contributor, pengembang dan penyelia naskah, komptensi dalam menetapkan dan mempersiapkan sumberdaya untuk keperluan editorial, komptensi dalam menyunting naskah, komptensi dalam membuat estimasi dan melakukan pengendalian biaya produksi, komptensi dalam memastikan dan menghitung biaya produksi, membuat estimasi dan melakukan pengendalian biaya publikasi elektronik, komptensi dalam menyiapkan dan membuat spesifikasi publikasi, komptensi dalam memberikan dukungan penjualan langsung dan kepuasan pelanggan mendukung apa yang dihipotesiskan Mincer (1958), Schultz (1961), dan Becker (1962) (dalam Blair, 2018) bahwa manusia sebagai modal utama yang mempengaruhi tingkat produktivitas. Tidak semua manusia sebagai modal dalam konteks ini, sejalan dengan tuntutan yang mengarah kepada special pekerjaan dan hasil yang berkualitas, maka manusia yang memiliki kompetensi tidak bisa ditawar lagi, sebagai modal utama dalam meningkatkan produktivitas. Seorang karyawan di bidang penerbit yang memiliki kompetensi akan mampu melaksakan pekerjaan sesauai dengan tuntutan standar komptensi yang ditentukan seperti pada unit -unit kompetensi yang distandakan oleh organisasi (Hornby dan Thomas, 1989: Hogg, 1993 : Kinkel dkk, 2017 : Asimov et al., 2009 : N. Chomsky, 1996)

\section{KESIMPULAN}

Dari hasil analisis data dan diskusi teroretik di atas, penulis menarik kesimpulan sebagai berikut:

Secara keseluruhan tingkat keperluan unit kompetensi sebagai panduan penyusunan SKKNI dari Badan Nasional Standarisasi Profesi (BNSP) yang dterapkan pada Politeknik Negeri Media Kreatif (PoliMedia) dalam kategori sangat tinggi. Secara khusus; 1) tingkat keperluan dalam mengidentifikasi dan mengevaluasi potensi pasar sehubungan dengan jenis naskah yang akan diterbitkan di program studi penerbit Politeknik Negeri Media Kreatif (PoliMedia) dalam kategori tinggi; 2) tingkat keperluan dalam mengkaji ulang rencana penerbitan yang telah dibuat apakah layak atau tidak di Politeknik Negeri Media Kreatif (PoliMedia) dalam kategori sangat cukup; c) tingkat keperluan dalam memilih penulis, kontributor, pengembang dan penyelia naskah yang cocok dan kompeten di program studi penerbit Politeknik Negeri Media Kreatif (PoliMedia) dalam keteogori cukup; d) tingkat keperluan dalam merundingkan dan menyepakati kerja sama penerbitan dengan para penulis, contributor, pengembang dan penyelia naskah di program studi penerbit Politeknik Negeri Media Kreatif (PoliMedia) dalam kategori sangat tinggi; e) tingkat keperluan dalam mempersiapkan sumberdaya untuk keperluan editorial di program studi penerbit Politeknik Negeri Media Kreatif (PoliMedia) dalam kategori cukup; f) tingkat keperluan dalam menyunting naskah di program studi penerbit Politeknik Negeri Media Kreatif (PoliMedia) dalam kategori cukup; g) 
tingkat keperluan dalam membuat estimasi dan melakukan pengendalian biaya produksi di Politeknik Negeri Media Kreatif (PoliMedia) dalam kategori cukup; h) tingkat keperluan dalam memastikan dan menghitung biaya produksi, membuat estimasi dan melakukan pengendalian biaya publikasi; i) elektronik di Politeknik Negeri Media Kreatif (PoliMedia) dalam kategori cukup; j) tingkat keperluan dalam menyiapkan dan membuat spesifikasi publikasi di Politeknik Negeri Media Kreatif (PoliMedia) dalam kategori cukup; k) tingkat keperluan dalam memberikan dukungan penjualan langsung dan kepuasan pelanggan di program studi penerbit Politeknik Negeri Media Kreatif (PoliMedia) dalam kategori tinggi.

\section{DAFTAR PUSTAKA}

Aimzhan Tulegenovna Makulova, at al. "Theory and Practice of CompetencyBased Approach in Education" (International Education Studies; Vol. 8, No. 8; 2015) pp. 183-184. ISSN 19139020 doi:10.5539/ies.v8n8p183 URL: http://dx.doi.org/10.5539/ies.v8n8p 183

Arikunto s, 2004. Pengantar Evaluasi Pendidikan. Jakarta: Rinekacipta

Asimov, E. G., \& Shchukin, A. N. (2009). New dictionary of metodological terms and concepts (the theory and practice of language teaching). Moscow: Publishing House: ICAR

Berkaliev, T. N., Zair-Bek, E. S., \& Tryapitsyna, A. P. (2007). Innovation and quality of school education. St. Petersburg, Publishing: Caro.

Dante, G., \& Ignacio, D. R. Professional competences: a classification of international models. (Journal Procedia, (46) 2012). pp. 1290-1296.

Hogg, B. (1993). European managerial competences. European Business Review, 93(2), 21-6.
Hossein Nassaji. "Qualitative and descriptive Data type data analysis Language Teaching Research" (Journals Permissions.nav 2015, Vol. 19 (2) pp. 129-132 DOI: $10.1177 / 1362168815572747$

Kinkel, S., Schemmann, B., \& Lichtner, R. "Critical competencies for the innovativeness of value creation champions: Identifying challenges and work-integrated solutions". (Journal Procedia Manufacturing, 9, 2017), 323-330.

Muhammad Riandy Arsin Siregar. "Kompetensi Yang Harus Di Miiliki Seorang Pustakawan (Pengelola Perpustaakaan) (Jurnal Iqra' Volume 09 No.02 Oktober, 2015), pp. 211

Ozhegov, S. I., \& Shvedova, N. Y. (1993). Dictionary of Russian language. Moscow: Az

Schippmann, J. S., Ash, R. A., Battista, M., Carr, L., Eyde, L. D., Hesketh, B., Kehoe, J. Pearlman, K., \& Sanchez, I. "The practice of competency modeling. Personnel" (Journal Psychology, 53. 2000), pp. 703-740.

Sugiyono, 2009. Metode Penelitian Kualitatit, Kuantitatif Dan R\&D. Bandung: Alfabeta

Tucker, S., \& Cofsky, K." CompetencyBased Pay on a Banding Platform". (ACA Journal, vol 3 (1) 1994), pp. 3045. 